\title{
Different genetic components in the Norwegian population revealed by the analysis of mtDNA and $\mathrm{Y}$ chromosome polymorphisms
}

\author{
Giuseppe Passarino*,1,2, Gianpiero L Cavalleri ${ }^{2}$, Alice A Lin ${ }^{2}$, Luigi Luca Cavalli-Sforza ${ }^{2}$, \\ Anne-Lise Børresen-Dale ${ }^{3}$ and Peter A Underhill ${ }^{2}$ \\ ${ }^{1}$ Dipartimento di Biologia Cellulare, Università della Calabria, Ponte Pietro Bucci c/da Arcavacata, 87030 Rende, \\ Italy; ${ }^{2}$ Department of Genetics, Stanford University School of Medicine, Stanford, California, CA 94305-5120, USA; \\ ${ }^{3}$ Department of Genetics, Institute for Cancer Research, University Clinic, The Norwegian Radium Hospital, \\ Montebello N0310, Oslo, Norway
}

The genetic composition of the Norwegian population was investigated by analysing polymorphisms associated with both the mitochondrial DNA (mtDNA) and Y chromosome loci in a sample of 74 Norwegian males. The combination of their uniparental mode of inheritance and the absence of recombination make these haplotypic stretches of DNA the tools of choice in evaluating the different components of a population's gene pool. The sequencing of the Dloop and two diagnostic RFLPs (Alul 7025 and Hinfl at 12308) allowed us to classify the mtDNA molecules in 10 previously described groups. As for the $\mathrm{Y}$ chromosome the combination of binary markers and microsatellites allowed us to compare our results to those obtained elsewhere in Europe. Both mtDNA and Y chromosome polymorphisms showed a noticeable genetic affinity between Norwegians and central Europeans, especially Germans. When the phylogeographic analysis of the $Y$ chromosome haplotypes was attempted some interesting clues on the peopling of Norway emerged. Although $\mathrm{Y}$ chromosome binary and microsatellite data indicate that $\mathbf{8 0 \%}$ of the haplotypes are closely related to Central and western Europeans, the remainder share a unique binary marker (M17) common in eastern Europeans with informative microsatellite haplotypes suggesting a different demographic history. Other minor genetic influences on the Norwegian population from Uralic speakers and Mediterranean populations were also highlighted. European Journal of Human Genetics (2002) 10, 521 -529. doi:10.1038/sj.ejhg.5200834

Keywords: Norway; population; mtDNA; Y chromosome

\section{Introduction}

Y chromosome specific and mtDNA polymorphisms, which are uniparentally inherited and are not reshuffled by recombination, are particularly useful tools for investigations involving the genetic structure and the history of human populations. Progress in elucidating Y chromosome variation $^{1-3}$ has catalysed the simultaneous study of both loci. ${ }^{4-10}$ In many cases different pictures emerged that have

*Correspondence: G Passarino, Dipartimento di Biologia Cellulare, Università della Calabria, Ponte Pietro Bucci c/da Arcavacata, 87030 Rende, Italy. Tel: 390984 492932; Fax: 390984 492911;

E-mail: g.passarino@unical.it

Received 25 September 2001; revised 2 May 2002; accepted 7 May 2002 been attributed to possible differential migration patterns $^{11,12}$ or other demographic phenomena. ${ }^{13,14}$

Recent studies involving $\mathrm{Y}$ chromosome and mtDNA sequence variation, have recently provided a refined portrait of the genetic variability of Scandinavian and northern European populations. ${ }^{8,9,15-17}$ These studies have also allowed the authors to make inferences on the relations between different populations of linguistic northern European population, ${ }^{17}$ to reappraise the origin of the Saami and to evaluate the influence of the Norse on other North Atlantic populations. ${ }^{8,9,16}$ These studies however, did not specifically address the possible origin of the 
Norwegians and the prehistoric migrations that affected Norway and Scandinavia. Here we report the results from Norwegian samples studied at relevant Y chromosome and mtDNA markers that have recently been used to reconstruct the prehistory of human groups in Europe. ${ }^{7,18,19}$ The haplotypes defined by these polymorphisms were extremely useful in understanding the re-peopling of Europe that occurred following the Last Glacial Maximum (LGM), the demic diffusion of Near Eastern agricuturalists that introduced agriculture in Europe: and the migration spread of Finno-Ugric Uralic speakers into Europe. Archaeological and genetic data indicates that these events strongly influenced the peopling of Norway and Scandinavia. ${ }^{19,20-22}$

The improvement of the climatic conditions following the end of the last glaciation about 12000 years ago gradually exposed the Scandinavian Peninsula, opening it to colonisation. Archaeological evidence suggests that groups of hunter-gatherers migrated from present day Poland and nearby regions. ${ }^{20}$ The subsequent arrival of agriculture to the Scandinavian Peninsula and possibly the IndoEuropean languages $^{21}$ transformed the lifestyle and possibly also influenced the indigenous gene pool. Finally, UralicFinno-Ugric speakers arriving in northern Scandinavia, probably from a region west of the Urals, ${ }^{17,23}$ had sporadic contacts with Norwegians. ${ }^{23}$ Here we define the genetic composition of Norway and attempt to distinguish possible signatures of these prehistoric events and to what extent: they involved gender modulated demographic phenomena.

\section{Materials and methods DNA samples}

The sample was composed of DNA collected from 74 young men collected during their medical check before the enrolment to the Norwegian army. The donors were a panNorwegian collection, although there was a slight majority from the central and southern part of the country. DNA extraction was performed using the ABI 340A extractor with phenol chloroform extraction followed by ethanol precipitation.

\section{Y chromosome binary polymorphism PCR and genotyping}

The markers studied were the same (22 markers) as those used to define the totality of the underlying structure of European Y chromosome binary variation. ${ }^{7}$ In addition, M21, M72, and M223 were also included in the haplotyping. The DHPLC technique ${ }^{24,25}$ was used for genotyping. Details regarding primers, fragment size, the specific DNA sequence variant and its location in the fragment are given in Underhill et al. ${ }^{2}$

\section{DHPLC analysis}

Unpurified PCR products were mixed at an equimolar ratio with reference $\mathrm{Y}$ chromosome amplicon of known allelic status and subjected to a $3-\min 95^{\circ} \mathrm{C}$ denaturation step followed by gradual reannealing from 95 to $65^{\circ} \mathrm{C}$ over $30 \mathrm{~min}$. Ten microliters of each mixture were loaded onto a DNASep(tm) column (Transgenomic, San Jose, CA, USA), and the amplicons were eluted in 0.1-M triethylammonium acetate, $\mathrm{pH} 7$, with a linear acetonitrile gradient at a flow rate of $0.9 \mathrm{ml} / \mathrm{min}$. Using appropriate temperature conditions, predicted by computer simulation (available at http://insertion.stanford.edu/melt.html) mismatches were recognised by the appearance of two or more peaks in the elution profile

\section{DNA sequencing}

Polymorphic and reference PCR samples were purified with QIAGEN (Valencia, CA, USA) QIAquick spin columns. Both strands were sequenced using the amplimers as sequencing primers and ABI Dye-terminator cycle sequencing reagents (Applied Biosystems, Foster City, CA, USA). Each cycle sequencing reaction contained $6 \mu \mathrm{l}$ of purified PCR product, $4 \mu \mathrm{l}$ dye terminator reaction mix, and $0.8 \mu \mathrm{l}$ of primer $(5 \mu \mathrm{M})$. Cycle sequencing was started at $94^{\circ} \mathrm{C}$ for $1 \mathrm{~min}$, followed by 25 cycles of $96^{\circ} \mathrm{C}$ for $10 \mathrm{~s}, 50^{\circ} \mathrm{C}$ for $2 \mathrm{~s}$, and $60^{\circ} \mathrm{C}$ for $4 \mathrm{~min}$. The sequencing products were purified with Centrifex(tm) gel filtration cartridges (Edge Biosystems, Gaithersburg, MD, USA) and analysed on an Applied Biosystems 373A sequencer.

\section{Y chromosome microsatellites}

The microsatellites studied included DYS $19^{26}$ and CAIIa, CAIIb. $^{27}$ One fluorescently labelled primer and one unlabelled primer for each locus was amplified in a $10 \mu \mathrm{l} \mathrm{PCR}$ reaction using reagent and PCR conditions as described in Ruiz Linares et al. ${ }^{28}$ Following PCR, $1 \mu \mathrm{l}$ of reaction product was loaded onto a standard $6 \%$ polyacrlyamide denaturing gel with electrophoresis performed in an ABI 373A sequencer. Internal size standards were added to each sample to permit quantitative sizing of each fragment using GeneScan 672 software.

\section{mtDNA genotyping}

D-loop sequencing of the HVSI fragment (16020-16383) was performed in all the samples. Primers and conditions are described in Graven et al. ${ }^{29}$ The status of the 7025 AluI and 12308 Hinfl sites were determinedas assayed as described in Torroni et al., ${ }^{30}$ to determine which samples fell in haplogroup $\mathrm{H}$ and $\mathrm{U}$ respectively.

\section{Statistical analysis}

A network of the mtDNA haplotypes was obtained with the program Network 2.0. ${ }^{31-33}$ The Fst and Фst quantities ${ }^{34}$ were calculated by means of the AMOVA program, which is included in the Arlequin package (http://lgb.unige.ch/ arlequin/). The significance of the pairwise distances was calculated by performing 10000 permutations. The data 
were not used to test for possible genetic structure in the Norwegian population.

\section{Results}

Table 1 reports the $\mathrm{Y}$ chromosome compound haplotypes (c-hts) found in our sample. A sample's c-ht was constructed by combining the allelic status of both the binary markers and microsatellite loci. Thirty haplotypes were observed. Common ancestry within microsatellite hts can be determined by examining binary markers. Using this classification, with the exception of one individual with EU16, all samples examined fall into one of four binary haplotypes defined as EU18, EU19, EU7 and EU14. ${ }^{7}$ The first three binary haplotypes account for $90 \%$ of the sample and are major components of Western and Central Europe. ${ }^{7}$ This is consistent with results by Helgason et al., ${ }^{8}$ Rosser et al. ${ }^{35}$ and Wilson et al. ${ }^{16}$ who, using a lower resolution system, found three major haplogroups in Norway (HG1, HG2, and HG3). Although these studies were

Table 1 Distribution of Norwegian $Y$ chromosome compound haplotypes. The first number denotes the binary Eu haplotype given in Figure 1, followed by DYS19 tetranucleotide repeats numbered 14 through 17 , followed by dinucleotide CAll $\mathrm{a} / \mathrm{b}$ structure as defined by QuintanaMurci et al. ${ }^{36}$

\begin{tabular}{|c|c|}
\hline C-Haplotype & $N=72^{a}$ \\
\hline EU16; 14; 4/1 & 1 \\
\hline EU18; $14 ; 3 / 1$ & 1 \\
\hline EU18; $14 ; 4 / 1$ & 2 \\
\hline EU18; $15 ; 4 / 1$ & 2 \\
\hline EU18; $16 ; 4 / 1$ & 1 \\
\hline EU18; $14 ; 5 / 1$ & 10 \\
\hline EU18; $16 ; 5 / 1$ & 3 \\
\hline EU18; $14 ; 7 / 1$ & 1 \\
\hline EU19; $15 ; 3 / 1$ & 6 \\
\hline EU19; $16 ; 3 / 1$ & 1 \\
\hline EU19; $15 ; 5 / 1$ & 1 \\
\hline EU19; $16 ; 5 / 1$ & 4 \\
\hline EU19; $17 ; 5 / 1$ & 2 \\
\hline EU19; $15 ; 6 / 1$ & 2 \\
\hline EU19; $15 ; 1 /-6$ & 1 \\
\hline EU7; $14 ; 3 / 1$ & 15 \\
\hline EU7.1; $14 ; 3 / 1$ & 1 \\
\hline EU7; $15 ; 3 / 1$ & 2 \\
\hline EU7; $14 ; 1 / 1$ & 3 \\
\hline EU7; $14 ; 4 / 2$ & 1 \\
\hline EU7; $16 ; 3 / 1$ & 2 \\
\hline EU7; $14 ; 1 /-6$ & 1 \\
\hline EU7; $16 ; 2 / 1$ & 1 \\
\hline EU7; $14 ; 1 /-5$ & 1 \\
\hline EU7: $14 ; 3 /-5$ & 1 \\
\hline EU7; $14 ; 3 / 2$ & 1 \\
\hline EU14; $15 ; 2 /-1$ & 1 \\
\hline EU14; $14 ; 4 /-1$ & 1 \\
\hline EU14; $14 ; 2 /-1$ & 1 \\
\hline EU14; $14 ; 1 /-1$ & 1 \\
\hline EU14; $14 ; 2 / 1$ & 1 \\
\hline
\end{tabular}

${ }^{a}$ Two of the samples, typed for mtDNA, are not included because they did not PCR-amplify for some of the $\mathrm{Y}$ chromosome analyses. unable to define any specific binary marker to positively define HG2, these lineages had a distinctive modal microsatellite haplotype. The binary haplotypes presented here provide an improved resolution and the phylogenetic relationships to previous data are shown in Figure 1 . It is likely that our M170 defined Eu 7 lineage represents at least a major part of their undifferentiated HG2 representatives. Also we infer that Eu 18 corresponds to HG 1 and Eu 19 to HG 3. Lastly, Eu14, which we define as a combination of the TAT and M178 mutations, relates to HG16. The Eu 7 associated markers, M21 and M72 were not observed. However one Norwegian Eu 7 chromosome displayed the M223 mutation (shown in Figure 1 as Eu7.1) that was also observed in two out of six German samples previously reported as just Eu 7 in Semino et al. ${ }^{7}$ The frequency of M223 elsewhere in Europe remains unknown. The haplotypes $\mathrm{Eu} \mathrm{9,Eu} 10$ and $\mathrm{Eu} \mathrm{11,} \mathrm{accounting} \mathrm{for} \mathrm{20 \%} \mathrm{of}$ Europeans, but uncommon in Northern Europe ${ }^{7}$ were not found in our survey. One Eu16 lineage was observed. The analysis of the DYS19 and CAII microsatelites attached to each binary marker reveals that 10 of the 17 Eu19 samples have two distinctive microsatellite motifs. Specifically six M17 marked chromosomes have the 15.3/1 (21/19) and four have the 16.5/1(23/19) structure, as defined by Quintana-Murci et al. ${ }^{36}$ Interestingly, while the $16.5 / 1(23 / 19)$ is common (65\%) in Eu19 lineages from Eastern Europe, the 15.3/1 (21/19) haplotype is absent in Eastern Europe and very rare elsewhere. ${ }^{37}$ Conversely, the microsatellite haplotypes for Norwegian Y chromosomes displaying EU 7 and EU18 are similar to those observed on the analogous $\mathrm{Y}$ chromosomes found in Central and Western Europe. ${ }^{7}$ The analysis of the pairwise distances calculated either taking into account the molecular distances among haplotypes or leaving them aside (Фst and Fst, respectively ${ }^{34}$ ) indicated a close affinity of Norwegians with Germans and other Central European populations (Czechs and Croatians) (Table 2).

Table 3 reports the mtDNA mutations found in the DLoop analysis of the Norwegian samples, together with the status of each sample at the 7025 AluI and 12308 Hinfl restriction sites. Data in Table 3 was used to construct the reduced Median Network shown in Figure 2. Table 4 summarises the frequency of mtDNA haplogroups observed in our sample. All of the nine haplogroups that are considered typical of Europe were found, and they accounted for the whole sample, except two samples that were N1 and L2, respectively. The most frequent haplogroup was $\mathrm{H}$, followed by haplogroup $U$. As previously reported for Northern Europeans most of the samples displaying haplogroup U fell in the U5 subgroup. Surprisingly high was the frequency of haplogroup J, considering its Mid East origin. ${ }^{19,38,39}$

\section{Discussion}

Both mtDNA and Y chromosome have helped to elucidate the re-population of Europe after the LGM (13000 BP) 


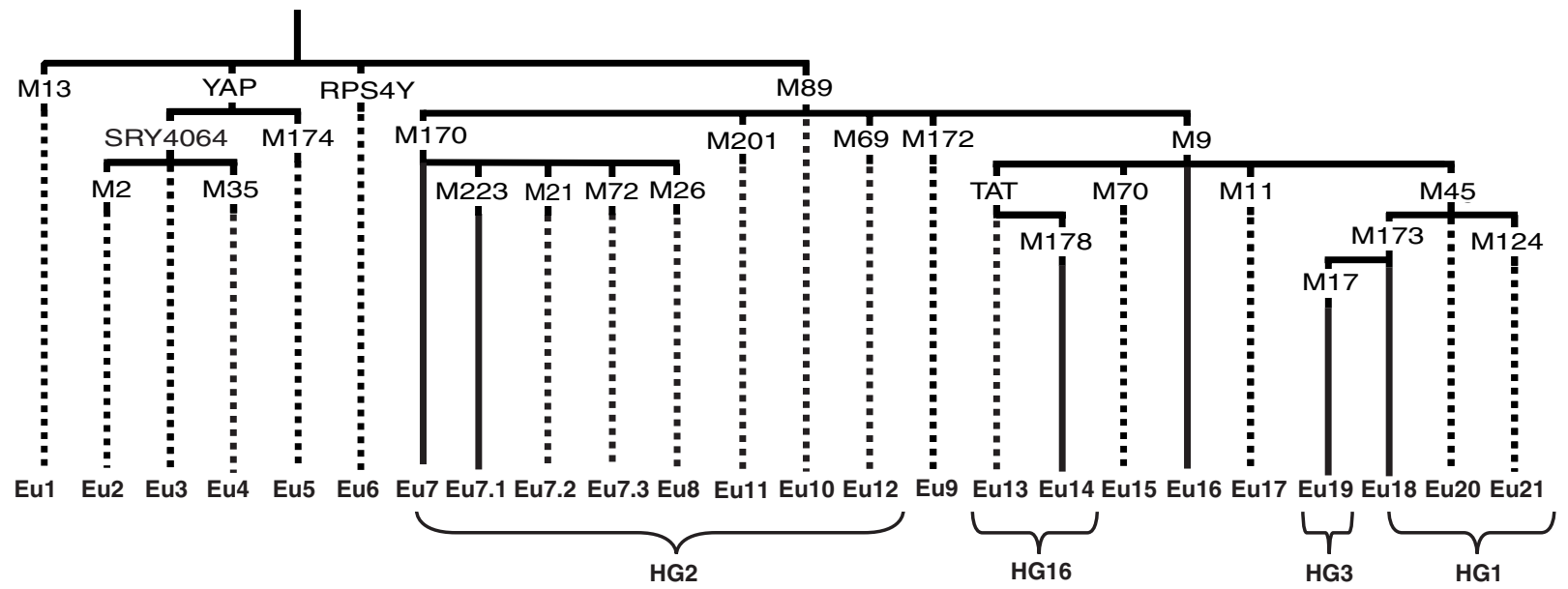

Figure 1 Maximum parsimony phylogeny of $25 \mathrm{Y}$ chromosome binary markers which define 22 haplotypes relevant in European populations. The numeration of the haplotypes follows that given in Semino et al. ${ }^{7}$ The haplotypes observed in Norwegians are indicated by solid lines. The remaining unobserved haplotypes are indicated by dashed lines. Correspondence between previously published HG1, HG2, H3 and H16 designations are shown in brackets.

Table 2 Pairwise $\Phi$ st and Fst of Norwegians with respect to other European Populations (Data from Semino et al. ${ }^{7}$ )

\begin{tabular}{|c|c|c|}
\hline Population & Фst & Fst \\
\hline Andalusia & $0.0918^{*}$ & $0.2003^{* * *}$ \\
\hline Basque (Spain) & $0.2035^{\star * *}$ & $0.3553^{* * *}$ \\
\hline Basque (France) & $0.1544^{* * *}$ & $0.3119^{* * *}$ \\
\hline Catalan & $0.1233^{* * *}$ & $0.2583^{* * *}$ \\
\hline French & 0.0348 & $0.1041^{* * *}$ \\
\hline Dutch & $0.0570^{*}$ & $0.1511^{* * *}$ \\
\hline German & -0.0149 & 0.0254 \\
\hline Czech & 0.0237 & $0.0376^{*}$ \\
\hline North Italian & $0.0721^{*}$ & $0.1733^{* * *}$ \\
\hline Calabrian & $0.1300^{\star \star *}$ & $0.1624^{* * *}$ \\
\hline Sardinian & $0.1483^{\star * *}$ & $0.1895^{* * *}$ \\
\hline Croatian & 0.0191 & 0.0189 \\
\hline Albanian & $0.1438^{\star * *}$ & $0.0956^{* * *}$ \\
\hline Greek & $0.1146^{\star * *}$ & $0.1178^{* * *}$ \\
\hline Macedonian Greek & 0.0391 & $0.0611^{*}$ \\
\hline Polish & $0.0780^{\star * *}$ & $0.0917^{* * *}$ \\
\hline Hungarian & $0.1111^{\star \star \star *}$ & $0.1472^{\star * *}$ \\
\hline Ukranian & $0.0398^{*}$ & $0.1239^{\star * *}$ \\
\hline Georgian & $0.1868^{* * *}$ & $0.2144^{* * *}$ \\
\hline Turk & $0.2080^{\star * *}$ & $0.2012^{\star * *}$ \\
\hline Lebanese & $0.2391^{* \star *}$ & $0.1954^{\star * *}$ \\
\hline Syrian & $0.1464^{\star * *}$ & $0.1487^{\star * *}$ \\
\hline Saami & $0.1422^{\star * *}$ & $0.0948^{* * *}$ \\
\hline Udmurts & $0.0839^{* * *}$ & $0.1175^{\star * *}$ \\
\hline Mari & $0.3555^{\star * *}$ & $0.3258^{\star * *}$ \\
\hline
\end{tabular}

The significance levels are indicated as ${ }^{*}<5 \%,{ }^{* *}<1 \%,{ }^{* * *}<0.1 \%$.

and assess the impact of the spread of agriculture on the descendants of the European Palaeolithic gene pool. ${ }^{7,18,22,35,37,38}$ Although distinctions were detected, indicative of some differences in demographic history regarding peopling of Europe, there is much concordance between the two uniparental loci. In particular they high- lighted that most (about 80\%) of the European genes descend from the small groups of humans that sought refuge from ice in a few scattered areas during the LGM, namely in northern Spain, in central Europe and Ukraine. $^{7,38}$ Because of drift, these populations during the long period of glaciation differentiated from each other. Thus, the present European populations harbour different genetic components that originated in distant locations. ${ }^{40}$ It is important, for addressing genetic research in a given population, to determine these components and evaluate their prevalence in the population.

The frequency of the $\mathrm{Y}$ chromosome binary defined haplotypes suggests that, at least from the male perspective, the genetic pool of the Norwegians is mainly composed of genes that were present in Europe as early as the Palaeolithic. In fact we do not observe those polymorphisms that were putatively brought to Europe by Neolithic farmers (that is p12f2, M201, YAP+/M35 $5^{7,10}$ ). Although we cannot conclude these markers are totally absent in the Norwegian population, this result indicates that their incidence is low. This is consistent with other results. ${ }^{8,16,35}$ In addition our observation of TAT/M178 lineages at 7\% corroborates previous observations, ${ }^{8,17,23}$ which have been interpreted as a signature of Uralic Finnno-Ugric speaking males migrating to northern Scandinavia and Finland about 5000 years ago. The presence of Eu14 in Norway suggests that some admixture between Norwegians and the FinnoUgric Uralic speakers of Scandinavia (Saami, Finns) has occurred. Interestingly, all the Y chromosome of our sample carrying the TAT/M178 mutations display different attached microsatellite haplotype, suggesting they come from sporadic cases of exchange and not by a single migration of a defined population. 
Table 3 Combined haplotypes of Norwegian mtDNA obtained by combining the data on the D-loop sequence and at the AluLI7025 and Hinfl12308 diagnostic restriction sites

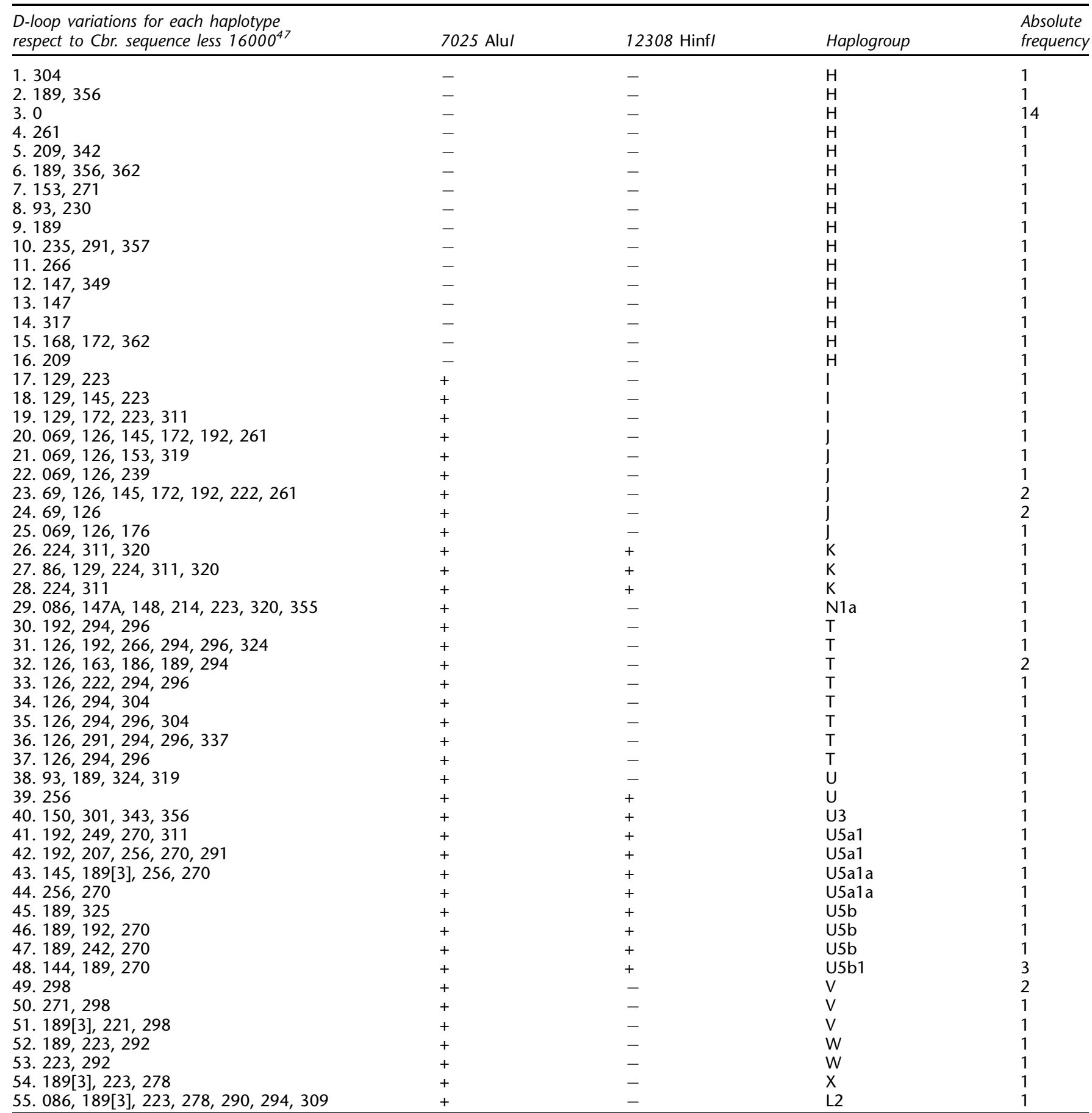

The notation 189[3] indicates that besides the 16189 transition $\mathrm{T} \rightarrow \mathrm{C}$, the deletion of one of the four Cs before the 189 position was observed.

Archaeological evidences have suggested that the core of the oldest populations colonising Scandinavia 1100012000 thousand years ago came from the present Germany. They probably went through the Jutland and the now submerged Doggerland, and then headed northward via the ice-free coastal area of Norway. Their lithic tools suggest they belonged to the Ahrensburgian culture, ${ }^{41,42}$ that thrived in central and eastern Europe (artifacts have been 
Table 4 Summary of the frequencies of mtDNA haplogroups

\section{$\mathrm{H}=29$}

$\mathrm{T}=9$

$\mathrm{J}=8$

$\mathrm{I}=3$

$\mathrm{X}=1$

$\mathrm{W}=2$

$\mathrm{U}=16$

$\mathrm{V}=4$

$\mathrm{N} 1=1$

$\mathrm{L} 2=1$

Tot. 74

found in Poland, Lithuania and Russia) in the so called 'Late Glacial', that is at the end of the LGM, when the increase of temperature and precipitation triggered the recession of the ice sheets. The analysis of many Ahrensburg sites and the related lithic tools has suggested that this culture started from the Dniepr valley in Ukraine, ${ }^{20}$ one of the sites were humans found refuge during the LGM. The analysis of $\mathrm{Y}$ chromosome polymorphisms in present European populations has indicated that $\mathrm{Eu} 19$ (that is also characterised by other Y chromosome markers: 49a,fht11, SRY 1532G ${ }^{35}$ ) expanded between 13000 and 7600 years ago from the Dniepr-Don Valley area, probably when groups that initially sought refuge in that area during the LGM were allowed to migrate by the improved climatic conditions to those regions of Europe previously covered by ice. ${ }^{7,37}$ In fact this $\mathrm{Y}$ chromosome lineage, is by far more frequent is eastern Europe with a decreasing westward gradient. In addition it is much more diversified in eastern European populations. The highest degree of diversification was observed in Ukranians. It is then possible that Ahrensburgian men, as well as most of the men descending from the Ukranian LGM refuge bore Eu19 Y chromosomes. The microsatellite haplotypes linked to M17 in Norwegian individuals represents indeed a subset of the repertoire observed in eastern Europe. In particular it was observed the prevalence of the 15.3/1 (21/19 repeats) and of the $16.5 / 1$ (23/19 repeats) haplotypes with their relative derivatives. The Eu19 16.5/1 haplotype is also very common in eastern Europe, while Eu 19 15.3/1 haplotype is common in Norway but very rare elsewhere. ${ }^{35}$ This peculiar pattern of microsatellites affiliated with EU19 may be explained by a founder effect, subsequent isolation in Norwegians (and possibly the Scandinavians) and eventual in loco expansion, as also observed elsewhere. ${ }^{37}$ If it seems reasonable to assume that most of the Ahrensburgian men bore the Eu19 Y chromosomes, it cannot be excluded that they mixed with other groups before moving northward to Norwegian coasts. In particular, late glacial central Europe was characterised by the expansion of northern Balkan groups, where the frequency of M170 Y chromosomes (EU 7) was probably very high. ${ }^{7}$ In addition, based on the differentiation of haplogroup $\mathrm{V}$ in Scandinavia, it also seems that groups coming from the northern Spain refuge entered Norway. ${ }^{22,43}$ Should this be true, it is likely that M173 Y chromosomes (EU18) also entered Norway during the late glacial.

With the exception of rather recent migrants from the Urals, it has been proposed that the appearance of domestic economies in Scandinavia arrived from central and northern Europe. These populations would have likely been Indo-European speakers that possibly fostered the Proto Baltic-Slavic-Germanic linguistic unity to the Baltic area and to north-eastern Europe. Specifically the Corded Wares culture from Central Europe (present Germany) and the Battle-Axe culture from Jutland. ${ }^{21}$ The spread of agriculture correlated with the Corded Wares-Battle Axe cultures and possibly involved the displacement of some of the previous populations, but in other cases, such as Poland and northern Russia it was mainly a cultural phenomenon. ${ }^{21}$ In Norway, hunting and fishing became a secondary source of sustenance. However it is debated if this was a consequence of the displacement of the previous populations, or of a cultural switch driven by a few newcomers. ${ }^{21}$

The present German gene pool shows a high frequency of Eu7 and Eu18 haplotypes. These haplotypes, which account for about $75 \%$ of the Norwegian Y chromosome pool, are then likely to have been brought to Norway by those groups who also brought the Indo-European languages and the agriculture. However, at present, it is not possible to evaluate how much this migration impacted the Norwegian gene pool. First, because it is not possible to distinguish between lineages brought in the late glacial time and those brought 5-6000 years ago. In addition, non-random mating phenomena may also play a role. It is possible that these cultures were composed of a subset of elite males, ${ }^{21}$ who reduced the reproductive success of other males and then the $\mathrm{Y}$ chromosome may emphasise the real genetic contributions of the central European migration to Norway. It has to be noticed that also part of the Eu19 lineage could have entered Norway with the migrations that brought the transition to agriculture. In fact, although very low in Germany, this lineage is very high in Poland, Hungary and in the former Czeckslovakia. However the network of microsatellite haplotypes attached to this lineage seems to suggest a long time in loco differentiation (see above). Either because of late glacial or of more recent migrations the Norway $\mathrm{Y}$ chromosome gene pool appears to be very close to present day Germans. In fact the $\Phi$ st and the Fst data indicate Germans and a few other Central European populations as being the closest to the Norwegians. When we compare our results with those based on different polymorphic systems, ${ }^{9,17}$ we can infer that these conclusions are also valid for Swedish, while Finns and Saami had a quite different genetic history with a great impact of Uralic Finno-Ugric speaking population.

The mtDNA polymorphisms had previously shown the genetic closeness of Norwegians with Germans, based on 


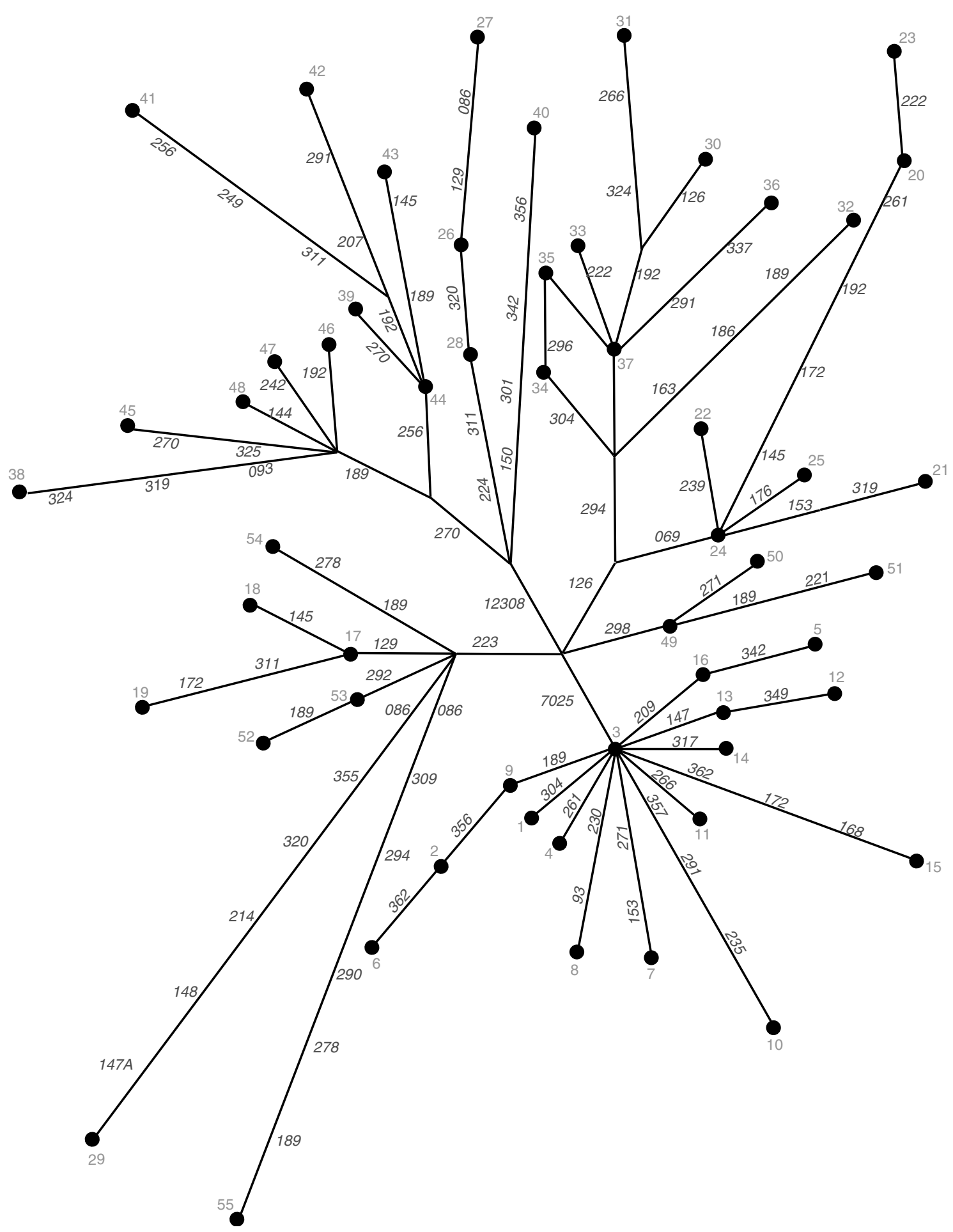

Figure 2 Reduced median network of the mtDNA haplotypes based upon HVSI mutations and the 7025Alul and 12308 Hinfl sites (see Table 3). The relevant mutations are indicated. The positions of the D-Loop mutations are given according to Anderson et al., ${ }^{47}$ less 16000 . It is worth mentioning that the connection of haplotype 55 to the tree is not the most parsimonious. In fact, considering that this molecule belongs to haplogroup L2, which is typically African and phylogenetically distant from the other haplotypes of the present tree, a separate independent connection has been forced. In addition, as the complete sequence data has shown that the 189325 type is in fact a U5b molecule where a back mutation occurred at $270,{ }^{48}$ haplotype 45 (which is indeed 189325 ) is shown to be derived via a back mutation at 270 . 
the statistic $\rho .^{8}$ Our data are consistent with this finding and support the $\mathrm{Y}$ chromosome representation of a strong genetic influence from central European groups, although it is less quantifiable. Like the TAT Y chromosomes (EU $13,14)$, mtDNAs with the $16144,16189,16270$ motif $^{44}$ indicate a low level of gene flow from Saami. As previously reported, $^{8}$ a low frequency of $\mathrm{H} 1$ mtDNA was observed (mutation at 16304). This haplotype has been proposed to mark the eastward spread of slavonic speakers from central Europe. ${ }^{45}$ Haplogroup J, possibly brought to Europe by Neolithic farmers coming from the Near East is found at a frequency of $10 \%$ in our sample. It has also been reported elsewhere at $7 \%$ in Norway. ${ }^{46}$ Given its frequency in Northern and Central Europe, it is likely it has been brought by the Germanic migrations to Norway. As previously noted ${ }^{7}$, the distribution of this haplogroup throughout Northern Europe indicates that during the spread of agriculture women moved throughout Europe, crossing group and cultural barriers more so than men. In addition, any asymmetric cultural factors that reduce the effective population size of men relative to women would influence the geographic patterns of mtDNA lineages relative to $\mathrm{Y}$ haplotypes. Positive selection is also a possible influence. The presence of mtDNA haplogroup J in our sample, and elsewhere in Northern Europe ${ }^{9,18}$ shows that its frequency in Norway is even higher than in those areas from where it probably arrived. It would be intriguing, although very speculative, to hypothesise that the climate of Northern Europe may have played a selective pressure where the uncoupling of oxidative phosphorylation and the consequent higher production of heat in $\mathrm{J}$ individuals ${ }^{39,40}$ may have led to an advantage, as previously suggested for the European groups during the glaciations ${ }^{39}$. One mtDNA molecule displayed an L2 haplotype, that is typically African, but is also sporadically found in Southern Europe and is likely to be a result of more recent gene flow. In conclusion mtDNA and $\mathrm{Y}$ chromosome analyses show a strong similarity between Norwegians and central European populations. However the Y chromosome locus has allowed us to apportion the genetic variability of Norwegians, indicating the components that are present in their gene pool. This information may constitute an important basis when complex genetic traits are studied in Norway. Further analysis is necessary to better understand when, and which way each component entered Norway. For this aim we are looking for additional local Y chromosome SNPs, that allow a refined phylogeographic analysis of the European late glacial migrations to be made.

\section{Acknowledgements}

We thank all the men who contributed their DNA to the research. We thank Toomas Kivisild and an anonymous reviewer for many constructive comments. The research was supported by NIH grants GM28428 and GM55273 to LLC Sforza.

\section{References}

1 Underhill, PA, Shen P, Lin AA et al: Y Chromosome Sequence Variation and the History of Human Populations. Nat Genet 2000; 26: 358-361.

2 Underhill PA, Passarino G, Lin AA et al: The phylogeography of Y chromosome binary haplotypes and the origins of modern human populations. Ann Hum Genet 2001; 65: 43-62.

3 Hammer MF, Karafet, TM, Redd AJ et al: Hierarchical patterns of global human Y-chromosome diversity. Mol Biol Evol 2001; 18: $1189-1203$.

4 Passarino G, Semino O, Quintana-Murci L, Excoffier L, Hammer M, Santachiara-Benerecetti AS: Different genetic components in the Ethiopian population, identified by mtDNA and Y-chromosome polymorphisms. Am J Hum Genet 1998; 62: 420-434.

5 Carvajal-Carmona LG, Soto ID, Pineda N et al: Strong amerind/ white sex bias and a possible sephardic contribution among the founders of a population in northwest Colombia. Am J Hum Genet 2000; 67: $1287-1295$.

6 Mesa NR, Modragón MC, Soto ID et al: Autosomal, mtDNA and Ychromosome diversity in amerinds: pre and post-Columbian patterns of gene flow in South America. Am J Hum Genet 2000; 67: $1277-1286$.

7 Semino O, Passarino G, Oefner PJ et al: The genetic legacy of Paleolithic Homo sapiens sapiens in extant Europeans: a Y chromosome perspective. Science 2000; 290: 1155-1159.

8 Helgason A, Hickey E, Goodacre S et al: mtDna and the islands of the North Atlantic: estimating the proportions of Norse and Gaelicancestry. Am J Hum Genet 2001; 68: 723-737.

9 Helgason A, Sigurethardottir S, Nicholson J et al: Estimating Scandinavian and Gaelic ancestry in the male settlers of Iceland. Am J Hum Genet 2000; 67: 697-717.

10 Underhill PA, Passarino G, Lin AA et al: Maori Origins, Y-chromosome haplotypes and implications for human history in the Pacific. Hum Mut 2001; 17: 271-280.

11 Seielstad MT, Minch E, Cavalli-Sforza LL: Genetic evidence for a higher female migration rate in humans. Nat Genet 1998; 20: $278-280$.

12 Oota H, Settheetham-Ishida W, Tiwawech D, Ishida T, Stoneking M: Human mtDNA and Y-chromosome variation is correlated with matrilocal versus patrilocal residence. Nat Genet 2001; 29: $20-21$.

13 Perez-Lezaun A, Calafell F, Comas D et al: Sex-specific migration patterns in Central Asian populations, revealed by analysis of Ychromosome short tandem repeats and mtDNA. Am J Hum Genet 1999; 65: 208-219.

14 Seielstad M: Asymmetries in the maternal and paternal genetic histories of Colombian populations. Am J Hum Genet 2000; 67: $1062-1066$.

15 Dupuy BM, Andreassen R, Flones AG et al: Y-chromosome variation in a Norwegian population sample. Forensic Sci Int 2001; 117: $163-173$.

16 Wilson JF, Weiss DA, Richards M, Thomas MG, Bradman N, Goldstein DB: Genetic evidence for different male and female roles during cultural transitions in the British Isles. Proc Natl Acad Sci USA 2001; 98: 5078-5083.

17 Zerjal T, Beckman L, Beckman G et al: Geographical, linguistic, and cultural influences on genetic diversity: Y-chromosomal distribution in Northern European populations. Mol Biol Evol 2001; 18: 1077 - 1087 .

18 Semino O, Passarino G, Quintana-Murci L et al: MtDNA and Y chromosome polymorphisms in Hungary: inferences from the palaeolithic, neolithic and Uralic influences on the modern Hungarian gene pool. Eur J Hum Genet 2000; 8: 339-346.

19 Richards MB, Macaulay VA, Bandelt HJ, Sykes BC: Phylogeography of mitochondrial DNA in western Europe. Ann Hum Genet 1998; 62: $241-260$.

20 Otte M: The northwestern European plain around 18,000 BP; in Soffer O, Gamble C (eds): The world at 18,000 BP. London: Unwin Hyman, 1990; Vol 1, pp 54-68. 
21 Dolukhanov PM: The Most Ancient North Europeans: Consensus is right?; in Julku $\mathrm{K}$ and Wiik $\mathrm{K}$ (eds): The roots of Peoples and Languages of Northern Eurasia. Turku, Finland: Societas Historiae Fenno-Ugricae., 1997.

22 Torroni A, Bandelt HJ, Macaulay V. et al: A signal, from human mtDNA, of postglacial recolonization in Europe. Am J Hum Genet 2001; 69: 844-852.

23 Zerjal T, Dashnyam B, Pandya A et al: Genetic relationships of Asians and Northern Europeans, revealed by Y-chromosomal DNA analysis. Am J Hum Genet 1997; 60: 1174-1183.

24 Underhill PA, Jin L, Lin AA et al: Detection of numerous Y chromsome biallelic polymorphisms by denaturing high performance liquid chromatography. Genome Res 1997; 7: 996-1005.

25 Oefner PJ, Underhill PA: Current Protocols; in Human Genetics. Wiley \& Sons., 1998, New York (Supplement 19) 7.10.1-710.12.

26 Roewer L, Arnemann J, Spurr NK, Grzeschik KH, Epplen JT: Simple repeat sequences on the human Y chromosome are equally polymorphic as their autosomal counterparts. Hum Genet 1992; 89: 389-394.

27 Mathias N, Bayes M, Tyler-Smith C: Highly informative compound haplotypes for the human Y chromosome. Hum Mol Genet 1994; 3: $115-123$.

28 Ruiz Linares A, Nayar K, Goldstein DB et al: Geographic clustering of human Y-chromosome haplotypes. Ann Hum Genet 1996; 60: $401-408$.

29 Graven L, Passarino G, Semino O et al: Evolutionary correlation between control region sequence and restriction polymorphisms in the mitochondrial genome of a large Senegalese Mandenka sample. Mol Biol Evol 1995; 12: 334-345.

30 Torroni A, Huoponen K, Francalacci P et al: Classification of European mtDNAs from an analysis of three European populations. Genetics 1996; 144: $1835-1850$.

31 Bandelt HJ, Forster P, Sykes BC, Richards MB: Mitochondrial portraits of human populations using median networks. Genetics 1995; 141: $743-753$.

32 Bandelt HJ, Forster P, Rohl A: Median-joining networks for inferring intraspecific phylogenies. Mol Biol Evol 1999; 16: 37-48.

33 Röhl A, Mihn DL: Network; A program package for calculating phylogenetic networks. Matehemathisches Seminar,. University of Hamburg, (1977).

34 Excoffier L, Smouse PE, Quattro JM: Analysis of molecular variance inferred from metric distances among DNA haplotypes: application to human mitochondrial DNA restriction data. Genetics 1992; 131: 479-491.
35 Rosser ZH, Zerjal T, Hurles ME et al: Y-chromosomal diversity in Europe is clinal and influenced primarily by geography, rather than by language. Am J Hum Genet 2000; 67: 1526-1543.

36 Quintana-Murci L, Semino O, Poloni ES et al: Y-chromosome specific YCAII, DYS19 and YAP polymorphisms in human populations: a comparative study. Ann Hum Genet 1999; 63: 153-166.

37 Passarino G, Semino O, Magri C et al: The 49af Haplotype 11 is a New Marker of the Eu19 Lineage which Traces Migrations from Northern Regions of the Black Sea. Hum Immun 2001; 62: $922-$ 932.

38 Richards M, Macaulay V, Hickey E et al: Tracing European founder lineages in the Near Eastern mtDNA pool. Am J Hum Genet 2000; 67: $1251-1276$

39 Sykes B: The molecular genetics of European ancestry. Philos Trans $R$ Soc Lond B Biol Sci 1999; 354: 131 - 138.

40 Malaspina P, Tsopanomichalou M, Duman T et al: A multistep process for the dispersal of a $\mathrm{Y}$ chromosomal lineage in the Mediterranean area. Ann Hum Genet 2001; 65: 339-349.

41 Sumkin VJ: On the ethnogenesis of the Saami:an archaeologial view. Acta Borealia 1990; 2: 3-20.

42 Larsson L (ed): The earliest settlement of Scandinavia and its relationship with neighbouring areas. Acta Archaeologica Lundensia; Series 80, No. 24. Stockholm, Sweden, 1996.

43 Torroni A, Bandelt HJ, D'Urbano L et al: mtDNA analysis reveals a major late Paleolithic population expansion from southwestern to northeastern Europe. Am J Hum Genet 1998; 62: 1137-1152.

44 Sajantila A, Lahermo P, Anttinen T et al: Nucleotide Genes and languages in Europe: an analysis of mitochondrial lineages. Genome Res 1995; 5: 42-52.

45 Malyarchuk BA, Derenko MV: Mitochondrial DNA variability in Russians and Ukrainians: implication to the origin of the Eastern Slavs. Ann Hum Genet 2001; 65: 63-78.

46 Opdal SH, Rognum TO, Vege A et al: Increased number of substitutions in the D-loop of mitochondrial DNA in the sudden infant death syndrome. Acta Paediatr 1998; 87: 1039-1044.

47 Anderson S, Bankier AT, Barrell BG et al: Sequence and organization of the human mitochondrial genome. Nature 1981; 290: $457-465$.

48 Finnila S, Hassinen IE, Ala-Kokko L, Majamaa K: Phylogenetic network of the mtDNA haplogroup $U$ in Northern Finland based on sequence analysis of the complete coding region by conformation-sensitive gel electrophoresis. Am J Hum Genet 2000; 66: $1017-1026$. 